\title{
PROPUESTA PARA UNA CORRECTA Y COMPLETA IMPLEMENTACIÓN DE LA REFORMA PENAL EN SONORA. ${ }^{1}$
}

Max Gutiérrez Cohen ${ }^{2}$

Sumario. Introducción II.Marco Normativo. III. Iniciativa de Nuevas Reformas Constitucionales en Materia de Competencias Federal y Locales para la Persecución y Sanción de los Delitos. IV.Información, Planeación y Presupuesto. V. Policía. VI.- Ministerio Público. VII. Defensoría Pública.VIII.Periciales. IX.Mediación y Conciliación. X. Impartición de justicia. XI. Evaluación, Supervisión y Ejecución de las Medidas Cautelares. XII. Formación y Capacitación de Abogados. XIII. Conclusiones

\section{Resumen}

En el presente documento se plantean algunas propuestas para que en el 2016 se termine de implementar en forma correcta e integral la Reforma Penal del 2008 en Sonora .

\section{Abstract}

This document raises some proposals so that the criminal reform of 2008 can be implemented in Sonora in 2016 in a correct and comprehensive way.

\section{Introducción}

La reforma penal requiere de la comprensión de sus múltiples ejes, para implementarla con éxito y evitar consecuencias negativas en la procuración e impartición de justicia en Sonora.

Los Ejes del Nuevo Sistema y los requerimientos esenciales para su implementación, son los que exponemos concretamente en los siguientes puntos:

\footnotetext{
${ }_{1}^{1}$ Ponencia presentada en el Foro sobre Justicia, convocado por el Partido Revolucionario Institucional, a través de su Consejo Político y la Fundación Colosio, A.C. 28 Nov de 2014.

${ }^{2}$ Maestro en Políticas de Seguridad Pública, Universidad de Sonora-Universidad Autónoma de Campeche, Magistrado Presidente del Supremo Tribunal De Justicia del Estado de Sonora 2006-2013,Catedrático de la Universidad de Sonora en diversas épocas y de otras Universidades Públicas y Privadas de las asignaturas de Derecho Agrario, Derecho Penal y Derecho Procesal Penal.
} 


\section{Marco Normativo.}

En primer término, es indispensable conocer a fondo los principios, lineamientos y derechos establecidos para el nuevo sistema de justicia penal, en la Reforma Constitucional publicada el dieciocho de junio de dos mil ocho, en el Diario Oficial de la Federación ${ }^{3}$, la cual debe entrar en vigor en toda la república a más tardar el dieciocho de junio de dos mil dieciséis.

Asimismo, es necesario el conocimiento de las Convenciones e Instrumentos Internacionales que obligan a nuestro país en la materia de los procedimientos penales y derechos humanos de los imputados y las víctimas de los delitos ${ }^{4}$.

También es necesario conocer tanto el Código Nacional de Procedimientos Penales, publicado el 5 de marzo de 2014 en el Diario Oficial de la Federación ${ }^{5}$, que establece las disposiciones para la operación de los tribunales, ministerio público, defensores, asesores de las víctimas y mediadores; el desarrollo de los juicios orales, los procedimientos abreviados y mecanismos alternativos de solución de controversias, así como el conocimiento de las múltiples leyes nacionales y locales relativas al nuevo sistema de justicia penal que ya se han expedido, aun cuando falta la expedición de leyes como las nacionales de mecanismos alternativos de solución de controversias y la de ejecución de sanciones, que son competencia del Congreso de la Unión de acuerdo con la reforma al artículo 73 fracción XXI constitucional, publicada el 8 de octubre de 2013 en el Diario Oficial de la Federación ${ }^{6}$, mismos ordenamientos nacionales que abrogarán a las leyes de

\footnotetext{
${ }^{3}$ Reforma Constitucional publicada el dieciocho de junio de dos mil ocho, en el Diario Oficial de la Federación, [consultado el 15 de noviembre de 2014 http://dof.gob.mx/nota_detalle.php?codigo=5046978\&fecha=18/06/2008]

${ }^{4}$ Resoluciones de la Suprema Corte de Justicia de la Nación y de la Corte Interamericana de Derechos Humanos, relativas a lo penal sustantivo y procesal, y a los derechos humanos [consultado 15 de noviembre de 2014 www.corteidh.or.cr/docs/casos/articulos/seriec_126_esp.doc]

${ }^{5}$ Código Nacional de Procedimientos Penales [consultado 15 de nov de 2014 http://www.diputados.gob.mx/LeyesBiblio/pdf/CNPP.pdf]
}

${ }^{6}$ Reforma al artículo 73 fracción XXI constitucional, publicada el 8 de octubre de 2013 en el Diario Oficial de la Federación [consultado en nov de 
esas materias que existen en nuestro estado y las de las demás entidades de la república.

Otros elementos para la formación de criterios sobre el nuevo sistema, están en las resoluciones de la Suprema Corte de Justicia de la Nación y de la Corte Interamericana de Derechos Humanos, relativas a lo penal sustantivo y procesal, y a los derechos humanos.

\section{III.- Iniciativa de Nuevas Reformas Constitucionales en Materia de Competencias Federal y Locales para la Persecución y Sanción de los Delitos.}

El día 27 de noviembre del año en curso, el Presidente de la República anunció que en los próximos días presentará diversas iniciativas de reformas constitucionales, entre otras, la que propondrá establecer las bases y lineamientos claros para redefinir y concretar reglas de competencia para perseguir y sancionar los delitos.

Esto significa la intención de que en las leyes quede claro cuáles son los delitos que competen a las autoridades federales, sean de policía, ministerio público y tribunales; y cuáles son los delitos que deban ser perseguidos y procesados por las autoridades de los estados y del Distrito Federal.

Es importante la revisión de las reglas de competencia actualmente establecidas, a partir de lo que dispone primordialmente el artículo 73 fracción XXI de la Constitución de los Estados Unidos Mexicanos, porque durante los últimos cinco años se ha reformado y adicionado en múltiples ocasiones, estableciendo facultades del Congreso de la Unión para expedir diversas leyes generales en materia de secuestro y trata de personas, de procedimientos penales, de mecanismos alternativos de solución de controversias, y de ejecución de penas, que regirán en la república en el orden federal y en el fuero común.

2014http://www.diputados.gob.mx/LeyesBiblio/proceso/cpeum/CPEUM_211_DOF_080 ct13.pdf] 
Pero además, creo que lo más delicado y que ahora emerge como motivo de la reforma que propone el Presidente de la República, es que también se ha venido legislando especialmente en relación con los delitos mencionados, estableciendo diversos supuestos en los que conocen de manera "concurrente" tanto las autoridades federales como las locales, y aquí cabe entender el dicho de que "la responsabilidad de todos es la responsabilidad de nadie".

Lo cierto es que a propósito de dicha concurrencia de competencias que establece por ejemplo, la Ley General de Salud cuando se trata de narcomenudeo (artículos 474 al 480); la Ley General para Prevenir y Sancionar Ios Delitos en Materia de Secuestro; la Ley General para Prevenir, Sancionar y Erradicar los delitos en materia de Trata de Personas y para la Protección y Asistencia a las Víctimas de estos Delitos $^{7}$ (artículo 5 y 6), se regulan supuestos en los que el conocimiento, persecución y enjuiciamiento de estos delitos, son a cargo de las autoridades federales y otros casos en los que serán competencia de las autoridades locales, no obstante que por la trascendencia y gravedad de los mismos, al igual que en la delincuencia organizada (que sí es delito de la competencia exclusiva de la federación), han cobrado tal importancia y trascendencia de carácter nacional e internacional, que amenazan y trastocan los derechos humanos y los más altos valores de seguridad pública y de estabilidad social.

Es previsible que la reforma anunciada corrija esas disposiciones constitucionales, que han dado la base para que la federación se deshaga de competencias que siempre debió haber mantenido bajo su esfera de responsabilidades, sobre todo las que corresponden al conocimiento $y$

\footnotetext{
${ }^{7}$ Ley General para Prevenir y Sancionar los Delitos en Materia de Secuestro; la Ley General para Prevenir, Sancionar y Erradicar los delitos en materia de Trata de Personas y para la Protección y Asistencia a las Víctimas de estos Delitos www.diputados.gob.mx/LeyesBiblio/doc/LGPSEDMTP.doc

Programa Nacional para Prevenir, Sancionar y Erradicar los Delitos en Materia de Trata de Personas y para la Protección y Asistencia a las Víctimas de estos Delitos 2014-2018.

[consultado 15 de nov de 2014

http://www.dof.gob.mx/nota_detalle.php?codigo=5343079\&fecha=30/04/2014]
} 
enjuiciamiento de los crímenes más relevantes para la nación entera, como el de la delincuencia organizada, el narcomenudeo que esencialmente es narcotráfico, el delito de trata de personas en el que es común que se traslade a las víctimas a través de los estados y muchas veces con destinos fuera del país.

Otro delito es el de la desaparición forzada de personas, que se ha venido tipificando en diversos códigos penales en el país, tanto el federal como locales, pero que puede ser de la competencia de las autoridades federales sólo cuando se surten los supuestos que establece el artículo 50 de la Ley Orgánica del Poder Judicial de la Federación ${ }^{8}$, y en el resto de los casos es de la competencia de los Estados o del Distrito Federal.

Al respecto, el Presidente de la República también anunció la iniciativa de Reforma Constitucional para que el Congreso de la Unión expida una ley "general" contra la desaparición forzada de personas, pero estimamos que sería preferible una auténtica ley "federal", en la que sólo las autoridades federales sean las competentes para perseguir y juzgar por estos delitos, pues basta señalar los gravísimos hechos en los que se ha privado de la Libertad y desaparecido a numerosos de personas, causando fuertes impactos de daño en todos los órdenes sociales, no sólo en los Estados donde se han cometido, sino a nivel nacional e internacional.

Creemos que no hay razón que justifique que los Estados y el Distrito Federal tengan alguna competencia, ni siquiera concurrente, sobre los delitos de desaparición forzada de personas y que deben ser las autoridades federales las que tengan la responsabilidad de prevenirlos, perseguirlos y juzgarlos, máxime que este delito se origina en acciones de agentes de la autoridad y si éstos fuesen locales, es lógico que debieran ser autoridades federales las responsables de perseguirlos y juzgarlos.

Asimismo, la concurrencia de competencias se ha aplicado con criterios de interpretación a veces contradictorios, causando atraso en la procuración e

\footnotetext{
${ }^{8}$ Ley Orgánica del Poder Judicial de la Federación, [consultado 15 de nov de 2014 http://www.diputados.gob.mx/LeyesBiblio/pdf/172_270614.pdf]
} 
impartición de justicia, y además existe la conocida "atracción de competencia", en la que la federación conserva una facultad de "atraer el caso", no obstante que existan evidencias del carácter federal del delito desde que se comete, 0 de que se da la conexidad clara del mismo con delitos federales.

El ejemplo clásico es cuando varias personas privan de la vida intencionalmente a uno o varios individuos, utilizando armas de uso exclusivo del ejército y que muestran claramente fuertes indicios del delito de delincuencia organizada, además del delito de portación y uso de tales armas prohibidas, previsto por la Ley Federal de Armas de Fuego y Explosivos ${ }^{9}$. Sucede frecuentemente en esos casos que primero se da la intervención de autoridades locales y si acaso se ejerce la facultad de atracción, o prospera la declinación de competencia, posteriormente entran al conocimiento del asunto las autoridades federales.

La cuestión esencial de esta iniciativa de reforma constitucional en materia de competencia, es que quede bien definido cuáles delitos le corresponden a las autoridades federales en forma exclusiva, para perseguirlos y juzgarlos, y se atienda para ello a la especie de crímenes que han trascendido con mayor impacto en perjuicio del país entero; que no se dé pauta a diversidad de criterios de interpretación y a evadir el cumplimiento de responsabilidades, o a perder tiempo y frustrar investigaciones y enjuiciamientos.

Estas reformas constitucionales tendrán que repercutir en fijar y responsabilizar con claridad lo que corresponde atender a las autoridades federales y qué compete a las locales.

Además, estas reformas competenciales serán de impacto necesario en la implementación del nuevo sistema de justicia penal, porque si quedan claras las disposiciones constitucionales y las reformas legales, para fincar la competencia de la Federación en los delitos mencionados y se evita la regulación de la concurrencia de competencias en este tipo de crímenes tan

\footnotetext{
${ }^{9}$ Ley Federal de Armas de Fuego y Explosivos. [consultado 15 de nov de 2014 http://www.diputados.gob.mx/LeyesBiblio/pdf/102.pdf]
} 
graves, lógicamente ello significará mayores necesidades de recursos administrativos, humanos, formación y capacitación de policías, peritos, ministerios públicos, jueces, etc., como parte de las responsabilidades de las autoridades federales, pero indudablemente también contribuirá a que tengamos un entendimiento claro de qué es lo que corresponde conocer, perseguir y juzgar a las autoridades federales y qué es lo que le compete a las autoridades locales.

\section{IV.- Información, Planeación y Presupuesto.}

La información sobre la incidencia delictiva en todos los municipios del Estado, del estado actual de las instituciones de seguridad pública, de procuración e impartición de justicia, de la defensoría pública y del sistema penitenciario en el Estado, de sus estructuras administrativa y humanas, así como de las características cuantitativas y cualitativas de sus servicios, es indispensable para planear todo lo que es preciso realizar con el fin de establecer el nuevo sistema de justicia penal.

Es importante considerar las funciones que a nivel nacional ha venido realizando la Secretaría Técnica para la Implementación del Sistema de Justicia Penal y los subsidios que se han otorgado a Sonora, mediante la gestión y proyectos presentados por la Comisión para la Implementación de la Reforma del Sistema de Justicia Penal del Estado de Sonora ${ }^{10}$. Asimismo, es necesario conocer las actividades de esta Comisión que tiene la función de coordinar a las diversas instituciones que intervienen en los procedimientos penales locales, gestionar recursos y realizar los proyectos que se aprueben, como son para infraestructura, capacitación y difusión para la instauración del nuevo sistema en Sonora.

Con toda esta información señalada en los párrafos que anteceden, la planeación para la implementación de la reforma penal debe partir del marco normativo ya citado en el punto II, atender las muy posibles reformas

\footnotetext{
${ }^{10}$ Comisión para la Implementación de la Reforma del Sistema de Justicia Penal del Estado de Sonora.

[consultado 15 de nov de 2014

http://www.dof.gob.mx/nota_detalle.php?codigo $=5329511$ \&fecha $=14 / 01 / 20$
} 
mencionadas en el punto III, y comprender todas las funciones legales de instituciones y actores que inciden en el nuevo sistema de justicia.

Esto es necesario hacerlo con una visión global y sistémica, porque las funciones de todos ellos se interrelacionan y deben ser instruidas bajo los mismos paradigmas y conceptos generales, con el fin de funcionar de manera coordinada y eficiente para avanzar constantemente en la procuración e impartición de justicia.

La planeación habrá de fincarse sobre esta base de entendimiento, de manera que se prevean las acciones a realizar, algunas en forma coetánea y otras sucesivas, atendiendo a un orden lógico, máxime cuando la propia reforma se implemente para que vaya entrando en forma gradual, por regiones o por delitos.

Así, se requiere de una visión global de todo el sistema y también particular de cada una de sus partes, con conceptos muy precisos y claros de los tiempos y los términos en que se prevean sus entradas graduales en operación.

Con base en la planeación, es lógico que se tienen que establecer los recursos presupuestales suficientes, que por cierto deben ser muy cuantiosos, para implementar la reforma cumpliendo con las metas y objetivos que se establezcan.

Sin una clara inteligencia de los ejes de la reforma, de una buena planeación y de presupuestos suficientes para implementar cada área o eje del nuevo sistema de justicia penal, lógicamente no es posible alcanzar las metas y objetivos, y en pocas palabras, cambiar y mejorar el sistema de justicia.

Los principales rubros en materia de recursos presupuestales son los relativos a la construcción de la infraestructura física, tales como edificaciones y equipamiento adecuados para el desarrollo de los juicios orales, la mediación y conciliación, la atención a víctimas del delito, las labores del ministerio público, defensores públicos y asesores de las víctimas, de manera que puedan funcionar en centros integrales de justicia, que permitan el acceso y la intercomunicación inmediata entre los diversos actores del sistema. 
Indudablemente las edificaciones y equipamiento, constituyen la parte más costosa y en Sonora existe la situación especial de que contamos con dieciséis distritos judiciales, destacando por su importancia en materia de número de procesos penales, los distritos de Hermosillo, Ciudad Obregón, Nogales, Agua Prieta, Caborca, San Luis Rio Colorado, Guaymas, Navojoa y Huatabampo, entre otros. Todos los distritos judiciales requieren de recintos suficientes y equipamiento adecuados para el funcionamiento de los nuevos procedimientos penales.

Los otros ejes de la reforma que también deben contemplarse con suficiencia de recursos en los presupuestos de egresos estatales y mediante la gestión de fondos federales, son los que a continuación enunciamos.

\section{Policía.}

La policía constituye una parte vital del nuevo sistema y a mi juicio, la que más requiere del análisis con experiencia y de soluciones que sean racionalmente suficientes y efectivas, para hacer posible un avance sustancial en las diversas funciones que tiene encomendada.

Los fenómenos delincuenciales sólo pueden ser prevenidos y evitados hasta donde sea humanamente posible, mediante la previsión y la puesta en marcha de un plan de incremento en las fuerzas de policía y en la capacitación continua institucionalizada, atendiendo a cada especie de delitos que cotidianamente se detectan en Sonora, sobre todo los de alto impacto y los más numerosos.

La información de delitos de homicidio, violación, extorsión, robos, daños incluyendo los de naturaleza imprudencial, entre otros, es indispensable para concretar las características de la planeación para el desarrollo de la policía, en lo cuantitativo y en lo cualitativo. Es importante distinguir lo necesario para capacitar a los policías según las grandes especies de delitos, con especialidades para la formación de mandos medios y superiores, independientemente de la capacitación para los policías comunes. 
Además, toda capacitación debe comprender ahora la instrucción sobre lo que es el nuevo sistema de justicia penal, y los requerimientos particulares relativos a la instrucción de policías en cuanto a técnicas de investigación, cadena de custodia y el rol a desempeñar en las audiencias en los tribunales penales.

Está claro que es mucho más lo que el nuevo sistema de justicia demanda de los policías, para que cumplan con las expectativas y necesidades de justicia de la sociedad Sonorense.

Es necesario estar atentos a la iniciativa que presente el Presidente de la República sobre las instituciones de policía ${ }^{11}$, porque no sólo aparece la intención de establecer el mando único, sino que en cada entidad exista una sola policía estatal.

Veremos cómo se procesa en el Congreso de la Unión esta iniciativa, pero advertimos la grave responsabilidad de analizarla y que se discuta amplia y profundamente, dado que las policías municipales son auxiliares del ministerio público para la persecución del delito y de los tribunales en los procesos judiciales, independientemente de las funciones de detención de personas en flagrante delito, de prevención del delito, de tránsito y de vigilancia que les corresponden.

En caso de suprimir a las policías municipales, tendría que tenerse la certeza plena de que previamente a dicha supresión, las Policías Estatales de cada entidad contaran con todos los recursos administrativos, humanos y materiales para cumplir con todas las funciones fundamentales que hasta la fecha corresponden en las leyes y reglamentos a las corporaciones de policía municipales.

De la normatividad que regule el nuevo sistema de justicia, de la experiencia de otros estados y países, y de la dinámica y complejidad de los fenómenos criminales, podemos desentrañar y poner en claro los retos y las tareas por

\footnotetext{
${ }^{11}$ Iniciativa de EPN Presidente de la República sobre las instituciones de policía, [consultado nov de 2014

www.excelsior.com.mx/nacional/2014/11/28/994660]
} 
realizar, si los vemos con un espíritu crítico constructivo, para avanzar en la procuración e impartición de justicia.

\section{VI.- Ministerio Público.}

Atendiendo al orden de ideas expresado en torno al rubro de la policía, también observamos la necesidad de que en la planeación y en los presupuestos se contemple el incremento en cuanto a la cantidad y la calidad de la capacitación de agentes de ministerio público, para cumplir con el amplio espectro de necesidades y atención en cuanto al número de delitos que se cometen y sus diferentes especies, sobre todo las que son de mayor impacto social.

Esto es para que la investigación sea oportuna, bien instruida conforme a la nueva normatividad y debidamente presentada ante los tribunales que ventilarán los procedimientos previstos en el Código Nacional.

Las condiciones para el desarrollo del ministerio público comprenden tanto el aspecto de infraestructura física que sea adecuada para este servicio público, como la creación de nuevas plazas del ministerio público y su capacitación atendiendo a las diversas especies de delito, de manera que sean suficientes para cubrir todo el Estado de Sonora.

\section{VII.- Defensoría Pública.}

La reforma constitucional requiere el desarrollo continuo de la institución de la Defensoría Pública, la cual lógicamente es un eje que debe ser apoyado presupuestalmente para mejorar su infraestructura física, los sueldos y contar con el incremento de defensores y su capacitación para que funjan con eficiencia en todo el territorio del Estado y cuenten con la capacitación suficiente para realizar sus funciones en los términos que prevé la Constitución.

La reforma penal tiene en los defensores públicos un eje más de todo el sistema de justicia y será uno de sus indicadores más objetivos para evaluarlo.

\section{VIII.- Periciales.}

En otro aspecto, es muy importante el desarrollo de la todo lo relativo a los servicios periciales y particularmente de los peritos con los que cuente el 
Estado en todas las regiones de incidencia delictiva importante, no sólo en cuanto a la infraestructura necesaria para sus funciones, como laboratorios e instrumentos y elementos de trabajo.

También es preciso entender que las especies de delitos de alto impacto social hacen indispensable que cada distrito judicial en el Estado y sobre todo los de mayor población, cuente con la infraestructura física e instrumentos y elementos, así como con peritos suficientes y capacitados para que funjan en la investigación de los delitos y en el desahogo presencial y oportuno de sus funciones en las audiencias, en las que deberán explicar y sustentar sus periciales.

Si no lográsemos estos elementos con las características cuantitativas y cualitativas señaladas, ello impactaría negativamente en la investigación de los delitos y entorpecería el desahogo de los juicios del nuevo sistema.

\section{IX.- Mediación y Conciliación.}

En la reforma constitucional, es claro el lugar y la importancia que se confiere a los mediadores y conciliadores para lograr las soluciones alternas de los conflictos, y ya es de sobra conocido que este nuevo sistema requiere que la gran mayoría de los casos penales que admiten la solución alterna de los conflictos, de acuerdo con el Código Nacional de Procedimientos Penales, no llegue al juicio oral. Así en experiencias del extranjero y conforme a las previsiones legales nacionales, se tiene que procurar que alrededor del $95 \%$ de los casos que ingresen ante los jueces de control y tribunales orales, no llegue al juicio oral propiamente tal, es decir, que se solucionen mediante acuerdos reparatorios o suspensión condicional del proceso, o en procedimientos simplificados o abreviados, porque el nuevo sistema no tendría la capacidad para procesar en juicio oral la diversidad de casos de delitos que se presenten ante los tribunales.

Establecer centros de justicia alternativa para lo penal y contar con mediadores y conciliadores profesionales suficientes y capaces para atender la problemática que la sociedad les presente, es una enorme tarea implicada en la necesaria planeación y asignación de presupuestos para contar con la 
infraestructura de tales centros en los diversos distritos judiciales, sobre todo los más poblados.

Se requieren mediadores y conciliadores que tengan la inteligencia, vocación y empeño indispensables para que logren la solución de la mayoría de las controversias que de acuerdo con el código pueden atenderse a través de estos medios alternativos.

\section{Impartición de Justicia.}

El eje de la impartición de justicia es indudablemente en el que se finca la mayor exigencia de la planeación y asignación de presupuestos necesarios para implementar la reforma, con el desarrollo de áreas específicas como el de la infraestructura consistente en edificaciones y equipamiento, la capacitación del personal para las funciones de jueces de control y de juicio oral, y las de magistrados. Además, el establecimiento del nuevo sistema de gestión administrativa para el ingreso, órden y control del flujo de los casos que ingresen a los tribunales penales.

Se trata de todo un sistema para el enjuiciamiento penal que a la vez debe operar coordinadamente con las instituciones del ministerio público y defensoría, así como los asesores de las víctimas, desde el ingreso de los asuntos a los jueces y a los tribunales de segunda instancia, y el control de las agendas de las audiencias de acuerdo con los múltiples procedimientos.

El Poder Judicial del Estado ha realizado múltiples actividades para la formación y capacitación de jueces para el nuevo sistema y en cuanto a la ejecución de sanciones, cuenta con tres jueces de ejecución que están en funciones. ${ }^{12}$ Tiene la gran tarea de proseguir e intensificar con base en la planeación, las tareas conducentes a la construcción de recintos judiciales, el equipamiento, la implementación del nuevo sistema de gestión administrativa y la capacitación de jueces de control, jueces de juicio oral y magistrados para operar el nuevo sistema, así como para la preparación del personal administrativo, máxime que de la calidad y eficiencia de los procedimientos

\footnotetext{
${ }^{12}$ http://www.stjsonora.gob.mx/noticias/443.htm
} 
penales, depende la legitimación o aceptación de la sociedad en general sobre la nueva justicia penal en Sonora.

\section{Evaluación, Supervisión y Ejecución de las Medidas Cautelares.}

El Código Nacional de Procedimientos Penales ${ }^{13}$ requiere el establecimiento de una institución federal y en cada entidad, que se encargue de la evaluación, supervisión y ejecución de las medidas cautelares que impongan los jueces a los imputados, incluyendo las relativas a la protección de las víctimas.

Estas medidas también tienen que ver con condiciones que se establezcan en acuerdos reparatorios y en la suspensión condicional del proceso penal. Es indispensable que se cree esta institución para que opere en todos los distritos judiciales, se le dote de recursos presupuestales suficientes y que se cumpla con las medidas como lo exige el código, pues si no se hace así, simple y sencillamente la incertidumbre sobre el cumplimiento de las medidas dejaría a los jueces sin elementos de información para saber si sus órdenes se están cumpliendo, si el inculpado está burlando las propias medidas y la víctima cuenta o no con alguna protección que el juez haya determinado otorgársele.

\section{Formación y Capacitación de Abogados.}

La formación en las universidades a través de los planes de estudios y programas de las materias, es fundamental para el establecimiento y operación del nuevo sistema de justicia penal.

La educación universitaria en las carreras de derecho debe comprender todos los elementos normativos del nuevo sistema de justicia y la realización de actividades prácticas para el desarrollo de las destrezas requeridas con el fin de fungir en los nuevos procedimientos, ya como jueces, ministerios públicos, abogados defensores o asesores de las víctimas. Es claro que la carrera de derecho y el posgrado en sus diversos niveles, están llamados a esta transformación de contenidos y formas educativas teóricas y prácticas, para cumplir con la función social ahora exigida.

\footnotetext{
${ }^{13}$ Código Nacional de Procedimientos Penales ,2014,op.cit
} 
En el mismo nivel de importancia, los abogados necesitamos participar con mucho interés en la capacitación sobre el nuevo sistema de justicia penal, aprovechando las asociaciones de abogados y todas las instituciones que nos brindan apoyo.

Además, tenemos la necesidad y estamos integrando círculos para el análisis, discusión, evaluación y búsqueda de propuestas y soluciones, con el fin de avanzar día a día, en los niveles de calidad profesional y contribuir en la medida de nuestras posibilidades en esta sana e indispensable misión de beneficio para Sonora.

\section{Bibliografía y Webgrafía}

GARCÍA RAMÍREZ Sergio, NEGRETE MORAYTA Alejandra, El Debido Proceso en la Jurisprudencia de la Corte Interamericana de Derechos Humanos, México 2010 [consultado 15 de nov de 2014 http://www.ijf.cjf.gob.mx/cursosesp/2012/jornadasitinerantes/procesoSGR.pdf]

Nuevas Reformas Constitucionales en Materia de Competencias Federal y Locales para la Persecución y Sanción de los Delitos.

[consultado 15 de nov de 2014

http://www.diputados.gob.mx/sedia/biblio/archivo/SAD-07-08.pdf]

Resoluciones de la Suprema Corte de Justicia de la Nación y de la Corte Interamericana de Derechos Humanos, relativas a lo penal sustantivo y procesal, y a los derechos humanos [consultado 15 de nov de 2014 www.corteidh.or.cr/docs/casos/articulos/seriec_126_esp.doc]

\section{Legislación}

Constitución Política de los Estados Unidos Mexicanos [consultado 15 de nov de 2014

http://www.dof.gob.mx/constitucion/marzo_2014_constitucion.pdf]

Código Nacional de procedimientos Penales

[consultado 15 de nov de 2014

http://www.diputados.gob.mx/LeyesBiblio/pdf/CNPP.pdf]

Comisión para la Implementación de la Reforma del Sistema de Justicia Penal del Estado de Sonora.

[consultado 15 de nov de 2014

http://www.dof.gob.mx/nota_detalle.php?codigo=5329511\&fecha=14/01/2014] 
Iniciativa de EPN Presidente de la República sobre las instituciones de policía, [consultado 15 de nov de 2014

www.excelsior.com.mx/nacional/2014/11/28/994660]

Ley General de Salud

[consultado 15 de nov de 2014

http://www.diputados.gob.mx/LeyesBiblio/ref/lgs.htm]

Ley General para Prevenir y Sancionar los Delitos en Materia de Secuestro, Reglamentaria de la Fracción XXI del Articulo 73 de la Constitución Política De Los Estados Unidos Mexicanos [consultado 15 de nov de 2014 http://www.diputados.gob.mx/LeyesBiblio/pdf/LGPSDMS_030614.pdf]

Programa Nacional para Prevenir, Sancionar y Erradicar los Delitos en Materia de Trata de Personas y para la Protección y Asistencia a las Víctimas de estos Delitos 2014-2018.

[consultado 15 de nov de 2014

http://www.dof.gob.mx/nota_detalle.php?codigo=5343079\&fecha=30/04/2014]

Ley Orgánica del Poder Judicial de la Federación, [consultado 15 de nov de 2014

http://www.diputados.gob.mx/LeyesBiblio/pdf/172_270614.pdf]

Ley Federal de Armas de Fuego y Explosivos.

[consultado 15 de nov de 2014

http://www.diputados.gob.mx/LeyesBiblio/pdf/102.pdf] 